\title{
PRIORITY EFFECTS IN CORAL REEF FISH COMMUNITIES
}

\author{
Glenn R. Almany ${ }^{1}$ \\ Department of Zoology, Oregon State University, Corvallis, Oregon 97331-2914 USA
}

\begin{abstract}
Demographically open communities are often viewed as stochastically structured assemblages because most colonizing juveniles arrive via unpredictable dispersal mechanisms. However, interactions between established residents and incoming juveniles may affect juvenile persistence in species-specific ways and could therefore impose a degree
\end{abstract} of determinism on future community structure.

Using 16 spatially isolated communities of coral reef fishes, I conducted two experiments to determine how prior residency by two guilds of fishes affected juvenile recruitment. Each experiment factorially manipulated the presence and absence of two guilds: resident piscivores (groupers and moray eels) and interference competitors (territorial damselfishes). In the first experiment, guilds were manipulated via selective removals, and subsequent recruitment (larval settlement minus mortality) was monitored for 44 days. In the second experiment, guilds were placed within large cages to prevent direct resident-juvenile interactions, while allowing for any cues produced by enclosed fishes, thereby testing whether incoming larvae used resident-derived cues to select or reject settlement sites. Colonizing juveniles were collected from each reef over 42 days to prevent confounding resident- and recruit-derived cues.

In the first experiment, piscivores inhibited recruitment of a damselfish (Pomacentridae) and a surgeonfish (Acanthuridae), and enhanced recruitment of a wrasse (Labridae). In contrast, territorial damselfishes inhibited recruitment of the damselfish and the wrasse, and enhanced recruitment of the surgeonfish. Observations of early recruitment patterns suggested that recruitment differences were established rapidly during the night or dawn periods shortly after settlement and before each daily census. In the second experiment, there was no evidence that larvae used resident-derived cues to select settlement sites, suggesting that recruitment differences in the first experiment resulted from differential mortality caused by direct resident-recruit interactions rather than differential larval settlement.

These results demonstrate that interactions between established residents and newly arrived juveniles can have a strong influence on juvenile persistence, and that such interactions appear to be strongest within hours of larval settlement. Furthermore, because resident effects were species specific, the present composition of these communities may impose a previously undocumented degree of determinism on their future structure.

Key words: Bahamas; community dynamics; competition; coral reef fish; damselfish; piscivore; predation; priority effect; recruitment; settlement; settlement cue.

\section{INTRODUCTION}

A fundamental goal in ecology is understanding the processes that influence the composition of communities (Morin 1999). A key factor influencing community structure is the relative abundance of juveniles entering the community. In relatively closed communities, most incoming juveniles are a product of reproduction within the community, and thus the relative abundance of incoming juveniles is directly related to the current structure of the community. In contrast, relatively open communities (e.g., most marine communities, as well as plant and insect communities with

Manuscript received 13 February 2002; revised 24 September 2002; accepted 23 October 2002; final version received 14 November 2002. Corresponding Editor: P. T. Raimondi.

${ }^{1}$ Present address: School of Marine Biology and Aquaculture, James Cook University, Townsville, Queensland 4811 Australia. E-mail: Glenn.Almany @jcu.edu.au dispersive life-history stages) depend on external sources for most incoming juveniles (reviews by Sale 1991, Connolly and Roughgarden 1999, Knowlton and Jackson 2001). Because juvenile supply is often spatially and temporally unpredictable in open systems, there is commonly little relationship between the relative abundance of incoming juveniles and the current structure of the community (reviews by Knowlton and Jackson 2001, Morgan 2001). As a result, the initial composition of open communities is partially determined by stochastic juvenile supply. However, once juveniles have entered the community, a variety of other factors influence their persistence. Understanding how such factors affect the persistence of colonizing juveniles could provide insight into the mechanisms that influence the structure of open communities.

One factor that may have a strong influence on juvenile persistence is the types of organisms already present in the community. Interactions between newly 
arrived juveniles and established residents may affect juvenile survival in a species-specific manner, and thus can alter initial patterns of abundance generated by juvenile supply. For example, residents may consume or compete with incoming juveniles, thereby preventing or inhibiting their establishment in the community (e.g., Wilbur and Alford 1985, Lawler and Morin 1993, Ostfeld et al. 1997). These “priority effects," in which established individuals affect those that arrive later, are a common feature of ecological communities and have been documented in plants (e.g., Huston and Smith 1987, Burrows 1990, Bertness and Shumway 1993), sessile marine organisms (e.g., Connell 1961, Sousa 1979, Menge and Sutherland 1987), coral reef fishes (e.g., Shulman et al. 1983, Sweatman 1985, Steele 1997), and amphibians (e.g., Alford and Wilbur 1985, Wilbur and Alford 1985, Lawler and Morin 1993). Determining how species-specific priority effects influence juvenile persistence may prove useful in understanding temporal changes in community composition (Morin 1999).

Assemblages of coral reef fishes are classic examples of open communities (review by Sale 1991). Like most marine species, reef fishes produce planktonic larvae that spend weeks to months in the pelagic environment (Leis 1991, Victor 1991). Larvae disperse from their natal reefs in oceanic currents, although recent studies provide evidence that some larvae are locally retained at the scale of oceanic islands (Jones et al. 1999, Swearer et al. 1999). Larvae typically make a nocturnal transition from the plankton to reef or near-reef habitats, a process called "settlement" (Victor 1991). After settlement, counted juveniles are called "recruits," and the net process of settlement minus subsequent mortality until census is called "recruitment." A muchdebated issue concerns the extent to which patterns of relative abundance at settlement are reflected in recruitment and later community structure (reviews by Doherty and Williams 1988, Hixon 1991, Jones 1991, Sale 1991, Ault and Johnson 1998). That is, do initial patterns persist, or do postsettlement processes modify initial patterns?

One prominent view of reef fish communities is that they are unpredictable assemblages that are primarily structured by stochastic larval supply (Sale 1980, Sale and Douglas 1984, Sale et al. 1994). While stochastic larval supply is clearly an important feature of reef fish communities, more deterministic processes operating during or after settlement may influence community structure. For example, there is evidence that some settling larvae select particular types of habitat, which they detect using visual or olfactory cues (Elliot et al. 1995, Danilowicz 1996, Holbrook and Schmitt 1997). Furthermore, it has been demonstrated that similar assemblages of species develop in similar habitats (Syms and Jones 2000) and that the survival of newly settled fishes can differ among habitats (Beukers and Jones 1997). These studies indicate that habitat preferences by settling larvae and/or habitat-mediated survival of juveniles can be important determinants of community structure. However, the influence of interactions between newly settled juveniles and established residents within habitats has seldom been explored, even though studies have demonstrated that residents can affect both settlement and recruitment. For example, some reef fish larvae select settlement sites based on the presence or density of conspecifics, which they detect via chemical or visual cues (Sweatman 1988, Booth 1992). Settlement site selection in these studies occurred at the scale of individual coral heads, which could lead to both between-reef and within-reef patterns of recruit distribution. Furthermore, effects of prior residents on subsequent recruitment appear to be common. For example, resident damselfishes can inhibit heterospecific recruitment, presumably by acting aggressively toward incoming juveniles (Shulman et al. 1983, Sweatman 1983, 1985, Jones 1987, Risk 1998), and either facilitate (Sweatman 1983, 1985, Jones 1987, Booth 1992) or inhibit (Sale 1976) conspecific recruitment. Resident predators generally inhibit recruitment and cause increased recruit mortality (Shulman et al. 1983, Caley 1993, Carr and Hixon 1995, Beets 1997, Hixon and Carr 1997). However, previous studies documenting effects of residents on natural recruitment (Shulman et al. 1983, Sweatman 1985, Jones 1987, Caley 1993, Beets 1997, Risk 1998) were unable to determine whether such effects were due to differential larval settlement or differential recruit persistence.

Here I report the results from two related field experiments that tested whether and how prior residency by two guilds of fishes affected subsequent recruitment. I identified two common guilds of residents likely to influence juvenile persistence: "resident piscivores," including groupers and moray eels, and "interference competitors," consisting of territorial damselfishes. The first experiment addressed two questions: (1) does prior residence by these guilds affect recruitment, and (2) how quickly are recruitment patterns established? I predicted that both guilds would negatively affect the recruitment of all species, and that recruitment patterns would be established rapidly, within 48 hours of settlement. In the second experiment, I explored the mechanism by which residents affect recruitment. I tested whether settling larvae selected settlement sites based on the presence or absence of the two guilds to determine whether recruitment patterns were most likely due to differential recruit mortality or differential larval settlement. Specifically, I evaluated the hypotheses that settling larvae use the presence and absence of the two guilds to (1) select among reefs, (2) select sites within reefs, and that (3) larger larvae are more selective than smaller larvae. I predicted that larvae would not select settlement sites, among or within reefs, based on the presence or absence of either predators or interference competitors, and that selectivity did not depend on larval size. 


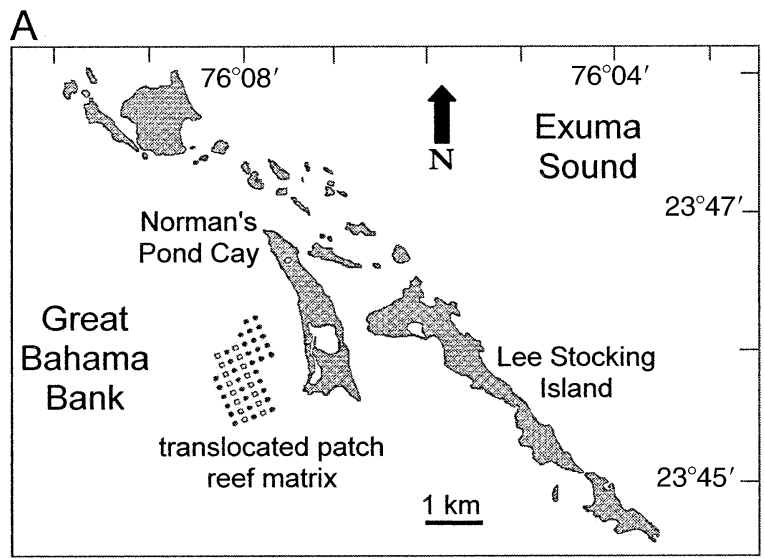

B

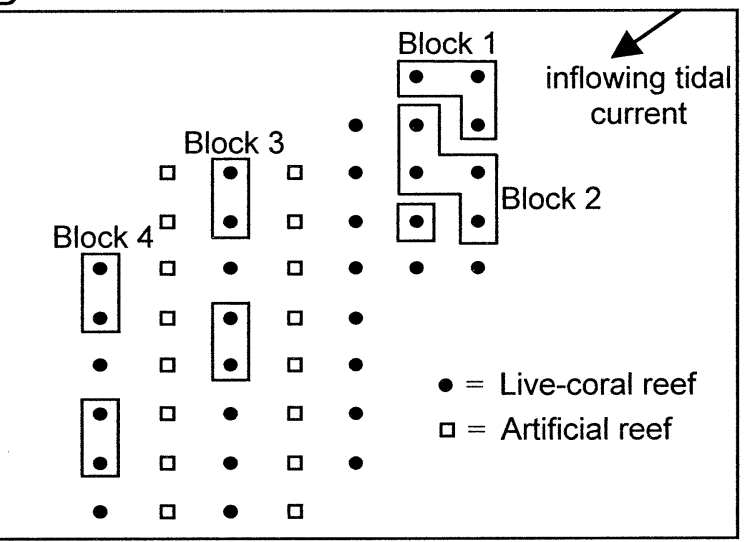

FIG. 1. Study site. (A) Position of translocated patch reefs with respect to nearby islands. (B) Spatial arrangement of reefs and the blocking scheme of live-coral reefs used in both experiments. Unused artificial reefs were constructed of concrete blocks. Each reef is separated from its closest neighbor by $200 \mathrm{~m}$ of sand and seagrass.

\section{Methods \\ Study site}

The study was conducted near the Caribbean Marine Research Center at Lee Stocking Island, Bahamas. This site is located in the Exuma archipelago, which separates the shallow Great Bahama Bank to the west from the deep waters $(>2000 \mathrm{~m}$ ) of the Exuma Sound to the east (Fig. 1A). All experiments were performed on a unique matrix of live-coral patch reefs that were translocated to a shallow sand flat on the leeward side of Norman's Pond Cay between 1991 and 1994 (Carr and Hixon 1995, Hixon and Carr 1997). The matrix included 32 reefs in five rows, at depths between 2 and $5 \mathrm{~m}$. Each reef consisted of 9-13 coral heads $($ mean $=$ $10.8, \mathrm{SD}=1.5$ ) of primarily three coral species: Montastrea annularis, Porites asteroides, and Siderastrea siderea. Average reef area was $6.6 \mathrm{~m}^{2}\left(\mathrm{SD}=1.0 \mathrm{~m}^{2}\right)$ and mean height was $0.5 \mathrm{~m}(\mathrm{SD}=0.07 \mathrm{~m})$. The design of the reef matrix minimized habitat variation among reefs by standardizing reef size, coral composition, and water depth among reefs. Reefs supported fish communities indistinguishable from those on nearby (within $5 \mathrm{~km}$ ) nonmanipulated patch reefs of similar size (personal observation), and had been unmanipulated for one year prior to these experiments. Each reef was separated from all others by $200 \mathrm{~m}$ of sand and seagrass and the closest naturally occurring reef was $>1 \mathrm{~km}$ from the edge of the matrix. I assumed that each newly settled recruit arrived via natural settlement, and that the disappearance of a recruit was due to mortality rather than postsettlement movement because (1) there is no evidence that newly settled recruits reenter the plankton after their first day on the reef (Kaufman et al. 1992, Holbrook and Schmitt 1997) and (2) small reef fishes rarely move between reefs separated by as little as $30 \mathrm{~m}$ (e.g., Doherty 1982, Hixon and Beets 1989).

\section{Study species}

Tagging studies demonstrated that resident fishes seldom moved between reefs in the matrix, with the exception of several transient predators (mostly jacks [Caranx spp.] and snappers [Lutjanus spp.]) (M. A. Hixon, personal communication). Resident piscivores were identified using two criteria: (1) a diet of at least $10 \%$ fishes by volume (Randall 1967) and (2) a strong tendency to retreat to the reef (as opposed to fleeing) when approached by a diver. The five resident piscivores included three diurnally active groupers (Serranidae: Cephalopholis cruentata [graysby], C. fulva [coney], and Epinephelus striatus [Nassau grouper]), and two nocturnally active moray eels (Muraenidae: Gymnothorax moringa [spotted moray] and G. vicinus [purplemouth moray]). Resident interference competitors were identified based on direct observations of aggression between resident fishes, and consisted of two common species of territorial damselfish: Stegastes leucostictus (beaugregory) and $S$. partitus (bicolor). Adults of both species are aggressive toward nearly all other fishes (Robertson 1996). Stegastes leucostictus is omnivorous, consuming algae, detritus, polychaetes, and fish material, whereas $S$. partitus is primarily planktivorous (Randall 1967, Emery 1973). Each reef had at least one adult damselfish prior to manipulations, and thus habitat differences among reefs resulting from damselfish modification was unlikely to influence either larval settlement or recruit survival (Ceccarelli et al. 2001).

\section{Experiment 1: Effects of prior residents}

To determine the effects of resident piscivores and territorial damselfishes on subsequent recruitment, I factorially manipulated the presence and absence of these two guilds on 16 of the 32 translocated patch reefs during the 1997 summer settlement season. I selected four blocks of reefs, each block consisting of four reefs, using two criteria: (1) reefs within each block had similar naturally occurring communities of 
fishes, which minimized confounding effects of variable species composition, and (2) reefs within a block were close to each other, which minimized confounding effects of variable larval supply. To meet these criteria, I compared the fish communities on all 32 reefs prior to manipulations using cluster analysis (Bray-Curtis distance and group average) and combined this analysis with reef location to select the best possible arrangement of reefs and blocks (Fig. 1B). Piscivore and damselfish densities varied among blocks, but were similar within blocks, and reflected the natural range of densities in the reef matrix prior to manipulations. Reefs were randomly assigned treatments within each block. There were four experimental treatments $(n=4$ reefs each): piscivores and damselfishes both present $(\mathrm{P}+\mathrm{D}+)$; piscivores present, damselfishes absent $(\mathrm{P}+\mathrm{D}-)$; piscivores absent, damselfishes present $(\mathrm{P}-\mathrm{D}+)$; and both piscivores and damselfishes absent $(\mathrm{P}-\mathrm{D}-)$.

Using scuba, I manipulated resident piscivores and damselfishes using the fish anesthetic quinaldine, hand nets, and a BINCKE (benthic ichthyofauna net for coral/kelp environments) net (Anderson and Carr 1998). After removing all recruits from each reef at the start of the experiment, I monitored subsequent recruitment by conducting a visual census of each reef approximately daily for $44 \mathrm{~d}$. Recruits that had settled the previous night were identified by their incomplete pigmentation and small size and recorded as "new settlers." Newly settled wrasse could not be reliably distinguished from those that had settled the previous several days. During each census, I verified treatment conditions and removed any immigrant piscivores and damselfishes. Immigration to the 16 reefs was negligible during the 44-d experiment (total of four piscivores and five adult damselfish).

To determine when recruitment patterns were established relative to nocturnal settlement, I tested whether mortality was relatively high during the first few hours of daylight postsettlement by comparing the number of new settlers recorded during early (0800-0900 hours) vs. late (1100-1200 hours) morning censuses. I conducted recruitment censuses each day $(\sim 15$ min per reef) between 0800 and 1200 hours. I divided the 16 reefs into four rows such that each row contained all four treatments to prevent confounding treatment with time-of-day. I systematically varied row censuses such that each row was censused in the early morning (0800-0900 hours) every fourth day.

\section{Experiment 2: Mechanisms underlying prior-resident effects}

The goal of the second experiment, conducted during the 1998 summer settlement season, was to determine whether recruitment differences observed in the first experiment were more likely due to differential larval settlement or differential recruit mortality. The experimental design was identical to that of the first exper-

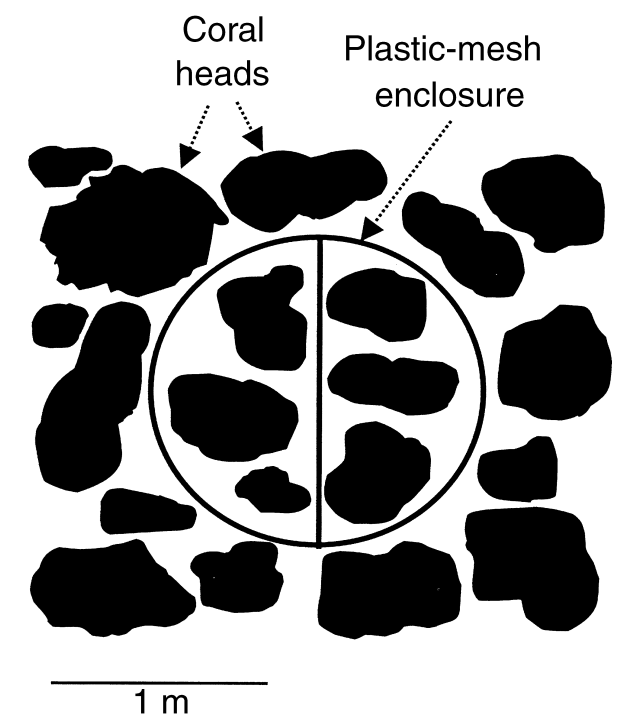

FIG. 2. Fish enclosure used to examine mechanisms underlying prior-resident effects. View of a single reef showing the arrangement of the enclosure and coral heads. Each plastic-mesh enclosure had an internal divider to keep piscivores and damselfishes separated in treatments where both were present, and each contained coral heads and rubble for shelter. Live coral heads outside enclosures served as settlement habitat for incoming larvae.

iment, except that piscivores and damselfishes were placed in large plastic mesh enclosures in the center of the reef. Small coral heads and rubble were placed inside enclosures to provide shelter for occupants. Coral heads that provided settlement habitat for recruits surrounded each enclosure, with $10 \mathrm{~cm}$ separating these coral heads from the enclosure. This manipulation eliminated direct interactions between enclosed fishes and recruits outside cages, but retained any cues produced by enclosed fishes that could be used by incoming larvae in selecting or rejecting a settlement site. An important assumption in this experiment was that settling larvae responded similarly to the presence of both caged and uncaged resident piscivores and adult damselfishes.

Each enclosure consisted of a cylindrical frame of metal rebar $(1.25 \mathrm{~cm}$ diameter) covered with plastic mesh (1.9-cm mesh vexar, Dupont, Wilmington, Delaware, USA). New recruits could pass through this mesh. Enclosures had a diameter of $165 \mathrm{~cm}$ and a height of $65 \mathrm{~cm}$ (total volume $=1.4 \mathrm{~m}^{3}$ ) and each had an internal divider of vexar (Fig. 2). All enclosures were identical regardless of treatment.

I used the same reefs and blocks as in the first experiment and randomly reassigned treatments $(\mathrm{P}+\mathrm{D}+$, $\mathrm{P}+\mathrm{D}-, \mathrm{P}-\mathrm{D}+$, or $\mathrm{P}-\mathrm{D}-)$ to reefs within each block with the constraint that each reef's treatment differed from its treatment in the first experiment, thereby controlling for any location effects between experiments. Each piscivore-present $(\mathrm{P}+)$ enclosure contained the average piscivore assemblage found on premanipulated 
reefs: two Epinephelus striatus, one Cephalopholis cruentata or C. fulva, and one Gymnothorax moringa or $G$. vicinus. Each damselfish-present $(\mathrm{D}+)$ enclosure contained the average damselfish assemblage on premanipulated reefs: two adult Stegastes leucostictus and two adult $S$. partitus. Where piscivores and damselfishes occurred together $(\mathrm{P}+\mathrm{D}+)$, each group occupied separate halves of the enclosure. Where piscivores occurred alone $(\mathrm{P}+\mathrm{D}-)$, the two E. striatus were placed in one-half of the enclosure and the C. cruentata or $C$. fulva and moray eel occupied the other. Where damselfishes occurred alone $(\mathrm{P}-\mathrm{D}+)$, each species occupied one-half of the enclosure. Preliminary trials showed that this arrangement resulted in the fewest antagonistic interactions between enclosed individuals. In most cases, prior residents from the same reef were used to stock the enclosure on that reef. Reefs where both piscivores and damselfishes $(\mathrm{P}-\mathrm{D}-)$ were removed had enclosures without fishes that contained small coral heads and rubble. Enclosed fishes generally showed no adverse effects of confinement. During periods of predictably low settlement (i.e., full moon), I fed enclosed piscivores pieces of fish and small swimming crabs (Portunidae). Enclosed damselfishes fed normally from substrates within cages or passing plankton.

I conducted a visual census of each experimental reef every other day for $42 \mathrm{~d}$. During each census, I removed any newly settled recruits, using hand nets and quinaldine, to eliminate any cues from recruits that might influence subsequent settlement and thus confound treatment effects. Prior to capture, I noted the position of each settler relative to the two halves of the enclosure on the two damselfish-present treatments $(\mathrm{P}+\mathrm{D}+$ and $\mathrm{P}-\mathrm{D}+$ ) to determine if there were any effects of enclosed fish on within-reef settlement location. I collected a random sample ( $n=25-52$ individuals per species) of newly settled recruits from the most abundant species in each family and measured each individual's total length (TL) to the nearest $0.1 \mathrm{~mm}$ using dial calipers to determine if site selectively was related to larval size.

\section{Data analysis}

In both the first experiment testing for prior-resident effects and the second experiment testing the underlying mechanisms of prior-resident effects, the experimental design was an unreplicated randomized block design with three factors: Blocks (random effect, four levels), Piscivores (fixed effect, two levels), and Damselfish (fixed effect, two levels). The two fixed effects were factorially manipulated. The full ANOVA model for this analysis would include the following terms: Block, Predators, Damselfish, and the interaction terms Predator $\times$ Damselfish, Block $\times$ Predator, and Block $\times$ Damselfish. However, to simplify the presentation of results, I eliminated the Block $\times$ Predator and Block $\times$ Damselfish interactions from the final ANOVA mod- el for each analysis for two reasons. First, there were no Block $\times$ Predator or Block $\times$ Damselfish interactions in initial visual inspections of the nine recruitment data sets presented in this study. Second, I further explored the possibility of significant interactions formally in analyses of the full model for each of the nine data sets, and there was only a single case in which a Block $\times$ Predator or Block $\times$ Damselfish interaction was significant at $\alpha=0.05(P=0.040$ in this single case). This represented a single significant interaction among the 18 interactions tested (nine ANOVAs, each with a Block $\times$ Predator and Block $\times$ Damselfish interaction), which is approximately what is expected if there were no underlying Block $\times$ Predator and Block $\times$ Damselfish interactions (i.e., the single significant interaction was due to chance alone). I therefore excluded these interactions from each ANOVA analysis.

In the first experiment testing for prior-resident effects, I compared differences in recruitment among treatments with ANOVA (model terms: Blocks, Piscivores, Damselfish, and Piscivore $\times$ Damselfish interaction). Because the presence of a significant interaction prevents interpreting each fixed effect alone, when interaction terms were significant $(P \leq 0.05)$, I provide a parameter estimate and corresponding $95 \%$ confidence interval, derived from the linear model, for each fixed effect at each level of the other fixed effect (Ramsey and Schafer 1997). When interaction terms were not significant $(P>0.05)$, I analyzed the additive model (model terms: Blocks, Piscivores, and Damselfish) to provide the effect size and $95 \%$ confidence interval, derived from the linear model, for each fixed effect. Note that the power of these tests was low, a priori, due to small sample size. To analyze differences in recruitment, I compared the average number of recruits on each treatment on the last day of the experiment (day 44). I chose this response for three reasons: (1) final recruit density is logically the best predictor of juvenile persistence and future community structure, (2) recruitment patterns continued to diverge at the conclusion of the experiment, and (3) final recruit density was consistent with the recruitment trajectory observed throughout the study. In the second experiment, designed to test the underlying mechanisms of priorresident effects, I used the same ANOVA procedure used in the first experiment to compare the total number of recruits collected from each treatment during the experiment. Note that the power of these tests was also low, a priori, due to small sample size. I compared the average size (total length [TL]) of recruits among treatments with one-way ANOVA, except for a single case in which unequal variance among treatments could not be corrected with transformation. In this single case, I used a nonparametric Kruskal-Wallis test (Sokal and Rohlf 1995). I analyzed within-reef differences in settlement location with a binomial test (Sokal and Rohlf 1995). Recruits that were collected from within enclosures were excluded from all analyses. To insure that 


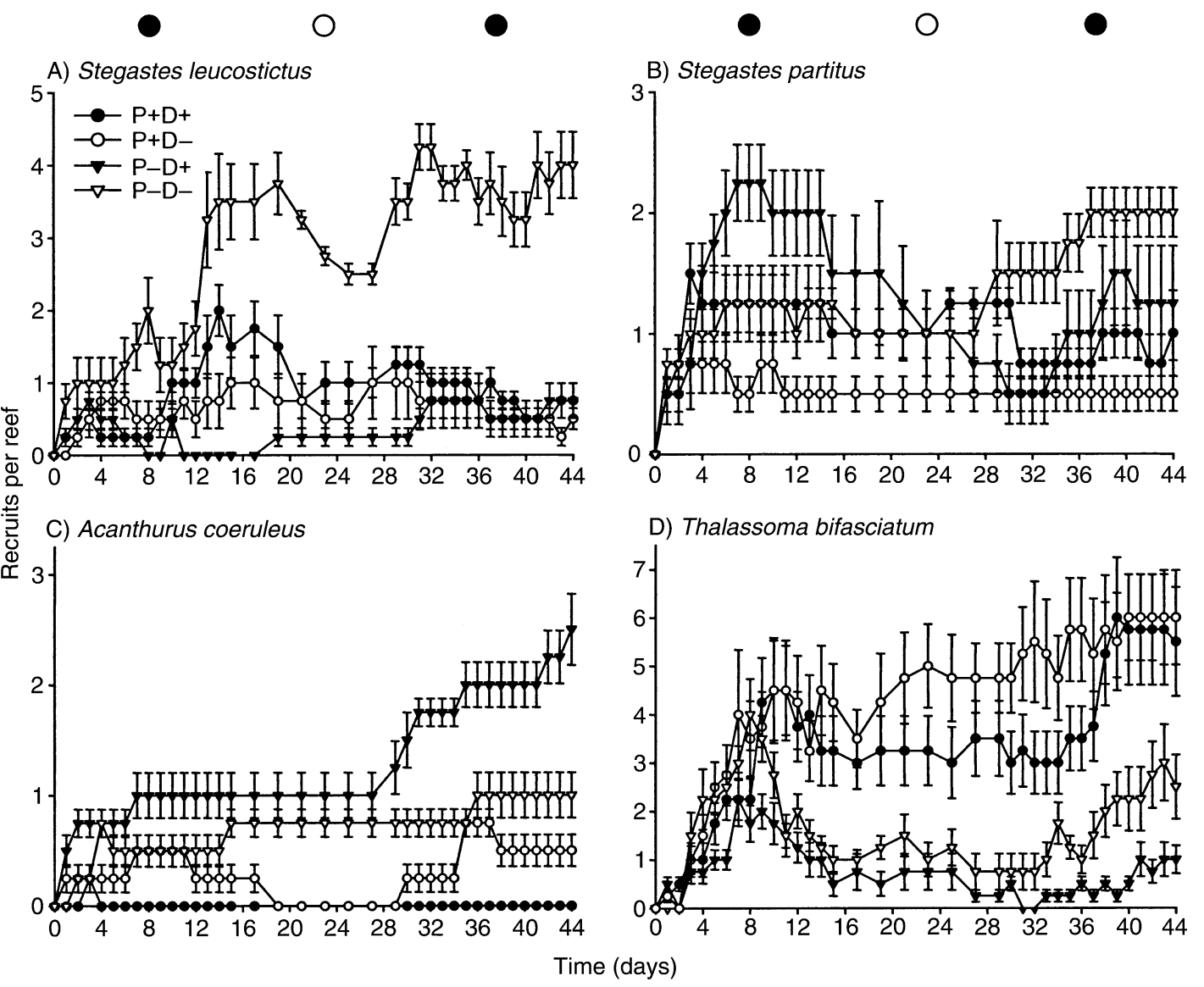

FIG. 3. Differential effects of prior residents on recruitment of four species. Relationship between recruitment (larval settlement minus mortality) and experimental treatments $(n=4$ reefs each) for the most abundant species in three families: (A) Stegastes leucostictus and (B) S. partitus (Pomacentridae); (C) Acanthurus coeruleus (Acanthuridae); and (D) Thalassoma bifasciatum (Labridae). Treatments consisted of presence $(+)$ or absence $(-)$ of resident piscivores $(\mathrm{P})$ and adult territorial damselfishes (D). Error bars indicate \pm 1 SE. The circles at the top of each column correspond to dates of the new moon (solid circle) and full moon (open circle). Note that the $y$-axis scale varies among plots.

ANOVA assumptions were met, I tested for homogeneity of variance using Levene's test and examined normal probability plots (Ramsey and Schafer 1997). Response variables transformed to correct unequal variance are noted in ANOVA tables. Effect sizes and corresponding $95 \%$ confidence intervals for transformed data were back calculated from transformed estimates, while error bars on graphs were calculated from untransformed data. All statistical analyses were conducted using SAS Institute statistical software (SAS version 6.12 and JMP version 4.0; SAS Institute 1989, 2000).

\section{REsults}

\section{Effects of prior residents}

During the 44-d experiment, I observed 340 new settlers from 22 species, $>90 \%$ of which were from three families: Pomacentridae (130 damselfish recruits), Acanthuridae (28 surgeonfish recruits), and Labridae (150 wrasse recruits). Resident piscivores and territorial damselfishes differentially affected recruitment of the most abundant species in each family.

Damselfish recruitment.-Most of the 130 newly settled damselfishes were from two species: the beaugregory damselfish, Stegastes leucostictus (79 recruits), and the bicolor damselfish, $S$. partitus (42 recruits). Both piscivores and adult damselfishes significantly affected S. leucostictus recruitment, and there was a significant interaction (Fig. 3A, Table 1A). Where adult damselfishes had been removed, piscivores reduced recruitment by an average (mean and $95 \% \mathrm{CI}$ ) of $3.5 \pm$ 2.0 recruits per reef, while in the presence of adult damselfishes, piscivores altered recruitment by $0.0 \pm$ 2.0 recruits per reef. Where piscivores had been removed, adult damselfishes reduced recruitment by 3.3 \pm 2.0 recruits per reef, while in the presence of piscivores, adult damselfishes increased recruitment by $0.3 \pm 2.0$ recruits per reef. The number of observed new settlers was highest where both piscivores and adult damselfishes had been removed (Table 2A). Re- 
TABLE 1. ANOVAs comparing the average number of recruits per treatment on the last day of the experiment (day 44) for (A) Stegastes leucostictus and (B) S. partitus (Pomacentridae), (C) Acanthurus coeruleus (Acanthuridae), and (D) Thalassoma bifasciatum (Labridae).

\begin{tabular}{|c|c|c|c|c|c|c|c|}
\hline \multirow[b]{2}{*}{ Source } & \multirow[b]{2}{*}{$\mathrm{df}$} & \multirow[b]{2}{*}{ ss } & \multirow[b]{2}{*}{ MS } & \multirow[b]{2}{*}{$F$} & \multirow[b]{2}{*}{$P$} & \multicolumn{2}{|c|}{ Levene's test $\dagger$} \\
\hline & & & & & & $F$ & $P$ \\
\hline A) S. leucostictus & & & & & & 2.661 & 0.091 \\
\hline Block & 3 & 2.50 & 0.83 & 0.54 & 0.669 & & \\
\hline Piscivores & 1 & 12.25 & 12.25 & 7.88 & 0.021 & & \\
\hline Damselfish & 1 & 9.00 & 9.00 & 5.79 & 0.040 & & \\
\hline$P \times D$ & 1 & 12.25 & 12.25 & 7.88 & 0.021 & & \\
\hline Error & 9 & 14.00 & 1.56 & & & & \\
\hline B) S. partitus & & & & & & 1.251 & 0.366 \\
\hline Block & 3 & 3.69 & 1.23 & 0.69 & 0.581 & & \\
\hline Piscivores & 1 & 3.06 & 3.06 & 1.72 & 0.223 & & \\
\hline Damselfish & 1 & 0.06 & 0.06 & 0.04 & 0.856 & & \\
\hline$P \times D$ & 1 & $\begin{array}{l}0.00 \\
1.56\end{array}$ & 1.56 & 0.88 & 0.374 & & \\
\hline Error & 9 & 16.06 & 1.78 & & & & \\
\hline C) A. coeruleus & & & & & & 0.816 & 0.584 \\
\hline Block & 3 & 3.50 & 1.17 & 2.33 & 0.142 & & \\
\hline Piscivores & 1 & 9.00 & 9.00 & 18.00 & 0.002 & & \\
\hline Damselfish & 1 & 1.00 & 1.00 & 2.00 & 0.191 & & \\
\hline$P \times D$ & 1 & 4.00 & 4.00 & 8.00 & 0.020 & & \\
\hline Error & 9 & 4.50 & 0.50 & & & & \\
\hline D) T. bifasciatum & & & & & & 1.191 & 0.391 \\
\hline Block & 3 & 87.50 & 29.17 & 5.90 & 0.017 & & \\
\hline Piscivores & 1 & 64.00 & 64.00 & 12.94 & 0.006 & & \\
\hline Damselfish & 1 & 4.00 & 4.00 & 0.81 & 0.392 & & \\
\hline$P \times D$ & 1 & 1.00 & 1.00 & 0.20 & 0.664 & & \\
\hline Error & 9 & 44.50 & 4.94 & & & & \\
\hline
\end{tabular}

cruitment of $S$. partitus was low, highly variable, and did not differ significantly among treatments (Fig. 3B, Table 1B). Piscivores reduced recruitment by $0.9 \pm 1.5$ recruits per reef, while adult damselfishes reduced recruitment by $0.1 \pm 1.5$ recruits per reef. The number of observed new settlers was highest where only adult damselfishes were present (Table 2B).

Surgeonfish recruitment.-Of 28 newly settled surgeonfish, 21 were Acanthurus coeruleus (blue tang). Piscivores and adult damselfishes both significantly affected recruitment of $A$. coeruleus, and there was a significant interaction (Fig. 3C, Table 1C). Where damselfishes had been removed, piscivores reduced recruitment by an average (mean and $95 \% \mathrm{CI}$ ) of $0.5 \pm$ 0.8 recruits per reef, while in the presence of damselfishes, piscivores reduced recruitment by $2.5 \pm 0.8$ recruits per reef. Where piscivores had been removed, damselfishes increased recruitment by $1.5 \pm 0.8$ recruits per reef, while in the presence of piscivores, damselfishes reduced recruitment by $0.5 \pm 0.8$ recruits per reef. The number of observed new settlers was highest where only adult damselfishes were present (Table 2C).

Wrasse recruitment.-Of 150 newly settled wrasse, 127 were Thalassoma bifasciatum (bluehead wrasse). Recruitment of $T$. bifasciatum was significantly influenced by piscivores, independent of adult damselfishes, and differed among blocks (Fig. 3D, Table 1D). Piscivores increased recruitment by an average (mean and $95 \% \mathrm{CI}$ ) of $4.0 \pm 2.4$ recruits per reef, and damselfishes reduced recruitment by $1.0 \pm 2.4$ recruits per reef. The

TABLE 2. Number of new settlers observed on each treatment during the experiment (44 d) for three species: (A) Stegastes leucostictus and (B) S. partitus (Pomacentridae), and (C) Acanthurus coeruleus (Acanthuridae).

\begin{tabular}{lcc}
\hline \hline Species & Treatment $\dagger$ & $\begin{array}{c}\text { Number of observed } \\
\text { new settlers } \ddagger\end{array}$ \\
\hline A) S. leucostictus & $\mathrm{P}+\mathrm{D}+$ & $18(5,3,4,6)$ \\
& $\mathrm{P}+\mathrm{D}-$ & $14(2,6,4,2)$ \\
& $\mathrm{P}-\mathrm{D}+$ & $9(2,4,2,1)$ \\
& $\mathrm{P}-\mathrm{D}-$ & $38(4,10,15,9)$ \\
B) S. partitus & $\mathrm{P}+\mathrm{D}+$ & $9(2,1,1,5)$ \\
& $\mathrm{P}+\mathrm{D}-$ & $4(0,2,2,0)$ \\
& $\mathrm{P}-\mathrm{D}+$ & $16(8,2,2,4)$ \\
C) A. coeruleus & $\mathrm{P}-\mathrm{D}-$ & $13(3,3,3,4)$ \\
& $\mathrm{P}+\mathrm{D}+$ & $1(0,0,0,1)$ \\
& $\mathrm{P}+\mathrm{D}-$ & $5(2,1,1,1)$ \\
& $\mathrm{P}-\mathrm{D}+$ & $10(4,3,1,2)$ \\
& $\mathrm{P}-\mathrm{D}-$ & $5(2,0,2,1)$ \\
\hline
\end{tabular}

$\dagger$ Abbreviations are: $\mathrm{P}$, piscivores; D, damselfishes; +, present; - absent.

$\ddagger$ Number outside parentheses is the total number of settlers observed across all four reefs in that treatment. Numbers inside parentheses are the number of settlers observed on each reef in that treatment, ordered by block (block 1 , block 2 , block 3, and block 4). 


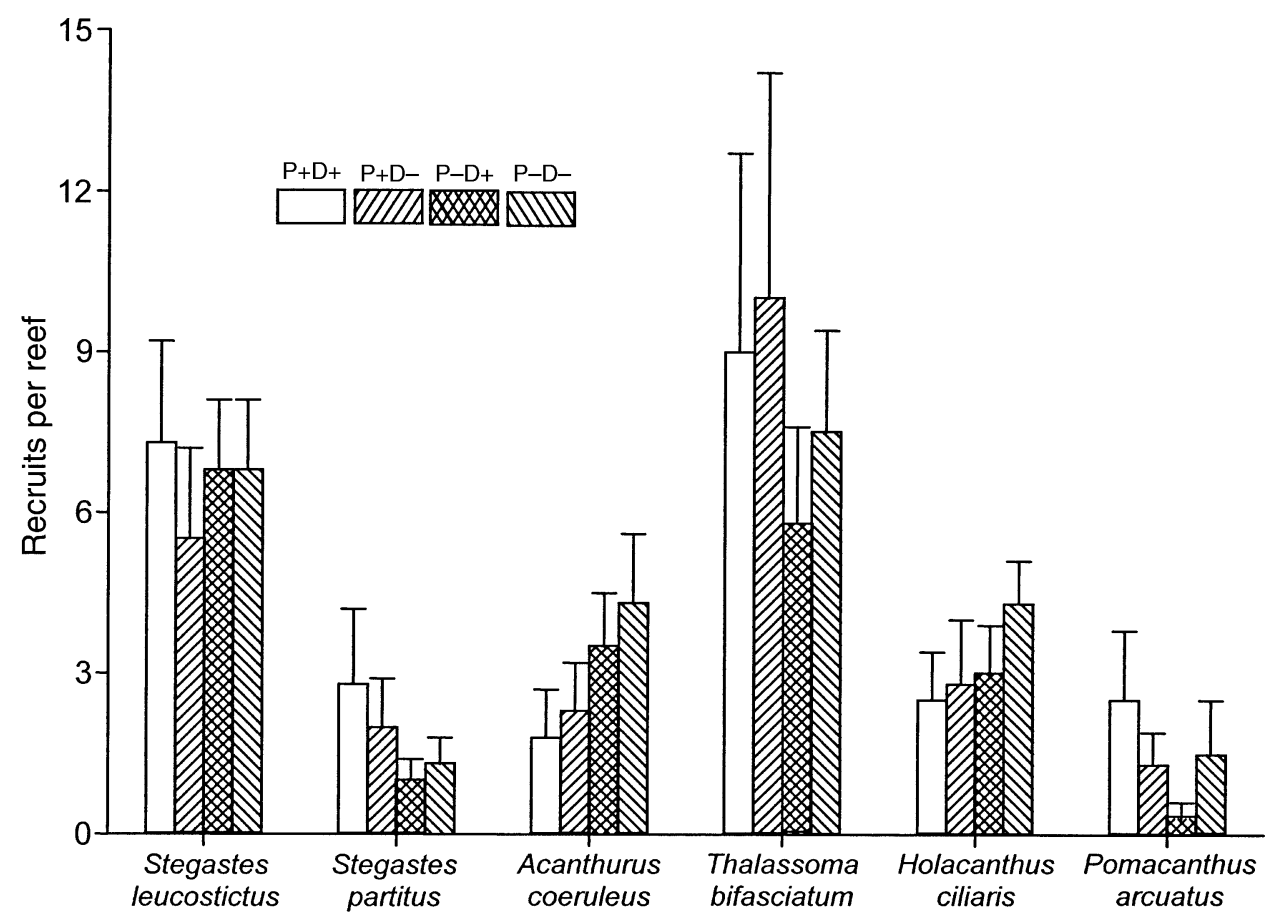

FIG. 4. Mechanisms underlying effects of prior residents on recruitment. Relationship between the average $(+1 \mathrm{SE})$ number of recruits collected per reef over 42 days in each experimental treatment $(n=4$ reefs each) for the most abundant species in four families: Stegastes leucostictus and S. partitus (Pomacentridae), Acanthurus coeruleus (Acanthuridae), Thalassoma bifasciatum (Labridae), and Holacanthus ciliaris and Pomacanthus arcuatus (Pomacanthidae). Treatments consisted of plastic mesh enclosures that contained $(+)$ or did not contain $(-)$ resident piscivores $(\mathrm{P})$ and adult territorial damselfishes (D). There were no significant differences among treatments, indicating no differential settlement due to prior-resident cues (see Discussion: Resident piscivores and territorial damselfishes ...).

average (SD) number of recruits per reef in each block was as follows: block $1=6.8$ (4.9), block $2=1.0$ (2.0), block $3=2.0$ (2.2), and block $4=5.3$ (2.2). The number of observed new settlers was not estimated due to the difficulty in distinguishing newly settled wrasse from those that had settled the previous several days.

\section{Timing of mortality}

The number of new settlers observed between early (0800-0900 hours) and late (1100-1200 hours) morning was similar for each category of recruits (early morning counts: all species $=50$ settlers, $S$. leucostictus $=21$ settlers, $S$. partitus $=10$ settlers, A. coeruleus $=4$ settlers; late morning counts: all species $=60$ settlers, $S$. leucostictus $=20$ settlers, $S$. partitus $=10$ settlers, $A$. coeruleus $=6$ settlers), indicating that mortality was negligible between these two periods. Comparisons of early and late morning counts of wrasse were precluded by the difficulty in distinguishing newly settled wrasse from those that had settled the previous several days.

\section{Mechanisms underlying prior-resident effects}

During the 42-d experiment, I collected 488 recruits from 25 species, $>90 \%$ of which were from four fam- ilies: Pomacentridae (153 damselfish recruits), Acanthuridae (53 surgeonfish recruits), Labridae (164 wrasse recruits), and Pomacanthidae (72 angelfish recruits).

Damselfish recruitment.-Of 153 damselfish recruits, 105 recruits were Stegastes leucostictus (beaugregory) and 28 recruits were $S$. partitus (bicolor). The average number of recruits per reef did not differ significantly among treatments for either species (Fig. 4, Table 3A, B). For S. leucostictus, piscivores reduced recruitment by an average (mean and $95 \% \mathrm{CI}$ ) of 0.4 \pm 2.2 recruits per reef, while adult damselfishes increased recruitment by $0.9 \pm 2.2$ recruits per reef. For $S$. partitus, piscivores increased recruitment by $1.3 \pm$ 1.7 recruits per reef, while adult damselfishes increased recruitment by $0.3 \pm 1.7$ recruits per reef. Average size of $S$. leucostictus recruits did not differ significantly among treatments (Table 4A). Average (SD) recruit size $(\mathrm{mm})$ on each treatment was as follows: $\mathrm{P}+\mathrm{D}+=12.9$ (0.3), $n=5$; $\mathrm{P}+\mathrm{D}-=13.2(0.4), n=5$; $\mathrm{P}-\mathrm{D}+=$ 12.4 (0.8), $n=7$; P-D- $=12.7$ (0.9), $n=8$.

Within-reef location with respect to enclosed fishes was noted for all S. leucostictus and S. partitus recruits collected from the two damselfish-present treatments $(\mathrm{P}+\mathrm{D}+$ and $\mathrm{P}-\mathrm{D}+)$. On $\mathrm{P}+\mathrm{D}+$ reefs, S. leucostictus recruits were evenly distributed (near piscivores $=12$ 
TABLE 3. ANOVAs comparing the total number of recruits collected from each treatment during the experiment (42 d) for (A) Stegastes leucostictus and (B) S. partitus (Pomacentridae), (C) Acanthurus coeruleus (Acanthuridae), (D) Thalassoma bifasciatum (Labridae), and (E) Holacanthus ciliaris and (F) Pomacanthus arcuatus (Pomacanthidae).

\begin{tabular}{|c|c|c|c|c|c|c|c|}
\hline \multirow[b]{2}{*}{ Source } & \multirow[b]{2}{*}{ df } & \multirow[b]{2}{*}{ SS } & \multirow[b]{2}{*}{ MS } & \multirow[b]{2}{*}{$F$} & \multirow[b]{2}{*}{$P$} & \multicolumn{2}{|c|}{ Levene's test $\dagger$} \\
\hline & & & & & & $F$ & $P$ \\
\hline A) S. leucostictus & & & & & & 2.91 & 0.073 \\
\hline Block & 3 & 81.19 & 27.06 & 6.75 & 0.011 & & \\
\hline Piscivores & 1 & 0.56 & 0.56 & 0.14 & 0.717 & & \\
\hline Damselfish & 1 & 3.06 & 3.06 & 0.76 & 0.405 & & \\
\hline$P \times D$ & 1 & 3.06 & 3.06 & 0.76 & 0.405 & & \\
\hline Error & 9 & 36.06 & 4.01 & & & & \\
\hline B) S. partitus & & & & & & 1.76 & 0.215 \\
\hline Block & 3 & 15.50 & 5.17 & 2.11 & 0.169 & & \\
\hline Piscivores & 1 & 6.25 & 6.25 & 2.56 & 0.144 & & \\
\hline Damselfish & 1 & 0.25 & 0.25 & 0.10 & 0.756 & & \\
\hline $\mathrm{P} \times \mathrm{D}$ & 1 & 1.00 & 1.00 & 0.41 & 0.538 & & \\
\hline Error & 9 & 22.00 & 2.44 & & & & \\
\hline C) A. coeruleus & & & & & & 2.51 & 0.104 \\
\hline Block & 3 & 3.69 & 1.23 & 0.25 & 0.857 & & \\
\hline Piscivores & 1 & 14.06 & 14.06 & 2.91 & 0.123 & & \\
\hline Damselfish & 1 & 1.56 & 1.56 & 0.32 & 0.584 & & \\
\hline$P \times D$ & 1 & 0.06 & 0.06 & 0.01 & 0.912 & & \\
\hline Error & 9 & 43.56 & 4.84 & & & & \\
\hline D) $T$. bifasciatum & & & & & & 0.903 & 0.532 \\
\hline Block & 3 & 168.69 & 56.23 & 1.74 & 0.229 & & \\
\hline Piscivores & 1 & 33.06 & 33.06 & 1.02 & 0.338 & & \\
\hline Damselfish & 1 & 7.56 & 7.56 & 0.23 & 0.640 & & \\
\hline$P \times D$ & 1 & 0.56 & 0.56 & 0.02 & 0.898 & & \\
\hline Error & 9 & 291.06 & 32.34 & & & & \\
\hline E) H. ciliaris & & & & & & 0.897 & 0.536 \\
\hline Block & 3 & 25.25 & 8.42 & 4.39 & 0.037 & & \\
\hline Piscivores & 1 & 4.00 & 4.00 & 2.09 & 0.183 & & \\
\hline Damselfish & 1 & 2.25 & 2.25 & 1.17 & 0.307 & & \\
\hline $\mathrm{P} \times \mathrm{D}$ & 1 & 1.00 & 1.00 & 0.52 & 0.488 & & \\
\hline Error & 9 & 17.25 & 1.92 & & & & \\
\hline F) $P$. arcuatus $\ddagger$ & & & & & & 2.20 & 0.138 \\
\hline Block & 3 & 3.24 & 1.08 & 4.95 & 0.027 & & \\
\hline Piscivores & 1 & 0.77 & 0.77 & 3.55 & 0.092 & & \\
\hline Damselfish & 1 & 0.03 & 0.03 & 0.12 & 0.738 & & \\
\hline$P \times D$ & 1 & 0.72 & 0.72 & 3.29 & 0.103 & & \\
\hline Error & 9 & 1.96 & 0.22 & & & & \\
\hline
\end{tabular}

Note: Nonsignificant interaction terms $(P>0.05)$ were dropped from the final model, and the reduced model was analyzed to estimate effect sizes and $95 \%$ confidence intervals for the main effects (see Results).

$\dagger$ Levene's $F$ test of the assumption of equal variance among treatments. $P>0.05$ indicates that this assumption has been met.

$\$$ Number of recruits $(X)$ was $\ln (X+1)$-transformed to correct unequal variance.

recruits, near damselfishes $=13$ recruits). On $\mathrm{P}-\mathrm{D}+$ reefs, more than twice as many $S$. leucostictus recruits were collected adjacent to adult $S$. leucostictus (near $S$. leucostictus $=17$ recruits, near $S$. partitus $=8$ recruits), a difference that was marginally significant (binomial test: $P=0.054)$. On $\mathrm{P}+\mathrm{D}+$ reefs, $S$. partitus recruits were evenly distributed (near piscivores $=6$ recruits, near damselfishes $=5$ recruits), while recruitment to $\mathrm{P}-\mathrm{D}+$ reefs was low (near $S$. leucostictus $=$ 0 , near $S$. partitus $=1$ recruit).

Surgeonfish recruitment.-Of 53 surgeonfish recruits, 47 recruits were Acanthurus coeruleus (blue tang). The average number of $A$. coeruleus recruits per reef did not differ significantly among treatments (Fig.
4, Table 3C). Piscivores reduced recruitment by an average (mean and $95 \% \mathrm{CI}$ ) of $1.9 \pm 2.3$ recruits per reef, while damselfishes reduced recruitment by $0.6 \pm 2.3$ recruits per reef. Average size of A. coeruleus recruits did not differ significantly among treatments (Table 4B). Average (SD) recruit size $(\mathrm{mm})$ on each treatment was as follows: $\mathrm{P}+\mathrm{D}+=34.3(1.1), n=6 ; \mathrm{P}+\mathrm{D}-=$ $34.1(0.8), n=4$; $\mathrm{P}-\mathrm{D}+=35.1(0.7), n=5$; $\mathrm{P}-\mathrm{D}-$ $=34.8(1.5), n=12$. The high mobility of surgeonfish recruits prevented comparison of their within-reef settlement locations.

Wrasse recruitment.-Of 164 wrasse recruits, 129 recruits were Thalassoma bifasciatum (bluehead). The average number of $T$. bifasciatum recruits per reef did 
TABLE 4. ANOVAs comparing average recruit size among treatments.

\begin{tabular}{|c|c|c|c|c|c|c|c|}
\hline \multirow[b]{2}{*}{ Source } & \multirow[b]{2}{*}{$\mathrm{df}$} & \multirow[b]{2}{*}{ ss } & \multirow[b]{2}{*}{ MS } & \multirow[b]{2}{*}{$F$} & \multirow[b]{2}{*}{$P$} & \multicolumn{2}{|c|}{ Levene’s test $\dagger$} \\
\hline & & & & & & $F$ & $P$ \\
\hline A) S. leucostictus & & & & & & 1.19 & 0.338 \\
\hline Treatment & 3 & 1.95 & 0.65 & 1.22 & 0.328 & & \\
\hline Error & 21 & 11.19 & 0.53 & & & & \\
\hline Total & 24 & 13.13 & & & & & \\
\hline B) A. coeruleus & & & & & & 1.22 & 0.324 \\
\hline Treatment & 3 & 3.15 & 1.05 & 0.68 & 0.576 & & \\
\hline Error & 23 & 35.73 & 1.55 & & & & \\
\hline Total & 26 & 38.88 & & & & & \\
\hline C) T. bifasciatum & & & & & & 0.10 & 0.961 \\
\hline Treatment & 3 & 1.85 & 0.62 & 1.20 & 0.321 & & \\
\hline Error & 48 & 24.74 & 0.52 & & & & \\
\hline Total & 51 & 26.59 & & & & & \\
\hline
\end{tabular}

Note: A random sample of recruits was collected from each treatment during the experiment (42 d) for (A) Stegastes leucostictus (Pomacentridae), (B) Acanthurus coeruleus (Acanthuridae), and (C) Thalassoma bifasciatum (Labridae).

$\dagger$ Levene's $F$ test of the assumption of equal variance among treatments. $P>0.05$ indicates that this assumption has been met.

not differ significantly among treatments (Fig. 4, Table $3 \mathrm{D})$. Piscivores increased recruitment by an average (mean and $95 \% \mathrm{CI}$ ) of $2.9 \pm 6.0$ recruits per reef, while adult damselfishes increased recruitment by $1.4 \pm 6.0$ recruits per reef. Average size of T. bifasciatum recruits did not differ significantly among treatments (Table $4 \mathrm{C})$. Average $(\mathrm{SD})$ recruit size $(\mathrm{mm})$ on each treatment was as follows: $\mathrm{P}+\mathrm{D}+=14.9(0.7), n=17 ; \mathrm{P}+\mathrm{D}-$ $=14.7$ (0.8), $n=15 ; \mathrm{P}-\mathrm{D}+=14.7(0.7), n=7$; $\mathrm{P}-\mathrm{D}-=14.4(0.7), n=13$. The high mobility of wrasse recruits prevented comparison of their withinreef settlement locations.

Angelfish recruitment.-Of 73 angelfish recruits, 50 recruits were Holacanthus ciliaris (queen) and 22 recruits were Pomacanthus arcuatus (gray). For each species, the average number of recruits per reef was independent of both piscivores and adult damselfishes (Fig. 4, Table 3E, F). For H. ciliaris, piscivores reduced recruitment by an average (mean and $95 \% \mathrm{CI}$ ) of 1.0 \pm 1.5 recruits per reef, while adult damselfishes reduced recruitment by $0.8 \pm 1.5$ recruits per reef. Recruitment of $H$. ciliaris differed significantly among blocks (Table 3E), and the average (SD) number of recruits per reef in each block was as follows: block 1 $=2.8$ (2.1), block $2=3.3(1.7)$, block $3=5.0$ (0.8), and block $4=1.5(0.6)$. For $P$. arcuatus, piscivores increased recruitment by 1.6 (95\% CI: -0.9 to 2.8 ) recruits per reef, while damselfishes reduced recruitment by 1.1 (95\% CI: -0.6 to 1.9 ) recruits per reef. Average size of $H$. ciliaris recruits did not differ significantly among treatments (Kruskal-Wallis test: $\chi^{2}=$ 4.61, df $=3, P=0.203$ ). Average (SD) recruit size $(\mathrm{mm})$ on each treatment was as follows: $\mathrm{P}+\mathrm{D}+=18.0$ (0.7), $n=8 ; \mathrm{P}+\mathrm{D}-=17.9$ (1.2), $n=8 ; \mathrm{P}-\mathrm{D}+=$ 19.6 (1.9), $n=9 ; \mathrm{P}-\mathrm{D}-=18.2$ (1.0), $n=11$.

Within-reef location with respect to enclosed fishes was noted for all $H$. ciliaris and $P$. arcuatus recruits collected from the two damselfish-present treatments $(\mathrm{P}+\mathrm{D}+$ and $\mathrm{P}-\mathrm{D}+)$. Location did not differ significantly for $H$. ciliaris on either $\mathrm{P}+\mathrm{D}+$ (near piscivores $=3$ recruits, near damselfishes $=3$ recruits) or $\mathrm{P}-\mathrm{D}+$ reefs (near $S$. leucostictus $=6$ recruits, near $S$. partitus $=4$ recruits), while $P$. arcuatus recruitment was generally low $(\mathrm{P}+\mathrm{D}+$ : near piscivores $=3$ recruits, near damselfishes $=1$ recruit; $\mathrm{P}-\mathrm{D}+$ : near $S$. leucostictus $=0$, near $S$. partitus $=1$ recruit).

\section{DISCUSSION}

In the first experiment, factorial removal of resident piscivores and territorial damselfishes resulted in significant, species-specific differences in recruitment among treatments for three taxonomically diverse species (Fig. 3). The two most likely mechanisms that generated these recruitment differences were (1) differential recruit mortality and (2) differential larval settlement. The observation of substantial differences among treatments in the number of new settlers observed during daily censuses in the first experiment (Table 2), which qualitatively reflected differences in recruitment observed throughout that experiment (Fig. 3 ), suggested that either (1) differential recruit mortality occurred prior to daily censuses, or (2) recruitment patterns were caused by differential larval settlement. I therefore conducted a second experiment, which tested whether settling larvae selected settlement sites based on the presence or absence of caged piscivores and territorial damselfishes. I found no evidence for differential settlement. Given the combined results of these two experiments, I believe the most parsimonious conclusion is that recruitment differences in the first experiment were caused by differential recruit mortality resulting from direct interactions between newly settled recruits and resident piscivores and territorial damselfishes. Furthermore, evidence sug- 
gests that differential recruit mortality was high within hours of settlement, before daily censuses. Finally, because density-dependent mortality, which alters relative abundance and thus community structure, is most common shortly after settlement (review by Hixon and Webster 2002), and recruit mortality generally decreases greatly following settlement (review by Hixon 1991, Caley 1998), recruitment differences at the conclusion of the first experiment ( $44 \mathrm{~d}$ ) were likely to be reflected in later community structure.

These conclusions depend on three key assumptions. First, larval settlement was relatively uniform among reefs in both experiments. While this was apparently the case in experiment 2, there is no evidence that settlement was uniform in experiment 1 . If settlement was spatially patchy in experiment 1 , differences in recruitment could have resulted from uneven settlement. However, this is unlikely because settlement would have to covary with treatment to generate significant differences among treatments, which seems unlikely unless settling larvae selected sites based on the presence of piscivores and damselfishes; results from experiment 2 do not support this conclusion. Second, settling larvae responded similarly to both uncaged and caged piscivores and damselfishes. If this was not true, then differential settlement could explain recruitment differences in experiment 1 . However, if larvae only settled differentially when piscivores and damselfishes were uncaged (experiment 1) but not when they were caged (experiment 2), then settling larvae must have both (1) detected the presence of piscivores and damselfishes and (2) determined whether or not they represented an actual threat (i.e., uncaged vs. caged). This explanation is less parsimonious than concluding that differential mortality caused differences in recruitment, and it requires complex decision making by settling fishes that involves weighing the relative threat of caged vs. uncaged piscivores and damselfishes with the threat of reentering the plankton. Third, direct interactions between settling larvae and piscivores and damselfishes did not affect the settlement process. That is, during the brief transition from the pelagic to reef environment, interactions with uncaged residents did not cause settling larvae to reenter the plankton and abandon settlement. If this were not true, then differential recruitment in the first experiment could have been caused by such interactions, which would result in differential settlement success among treatments. However, there is no evidence that interactions with residents cause larvae to reenter the plankton and abandon settlement at night, although some larvae released during the day avoid movement toward reefs with residents (review by Leis and McCormick 2002). In the only study to directly examine this question, Holbrook and Schmitt (1997) used infrared cameras to observe aggressive interactions between new settlers and residents and found that settlers never reentered the plankton and abandoned settlement, nor were they ever expelled from habitat, as a result of these interactions.

\section{Resident piscivores and territorial damselfishes as settlement cues}

Results from the second experiment support the predictions that larvae do not use the presence or absence of resident piscivores and territorial damselfishes to select either among reefs or within reefs, and that site selectivity is independent of larval size. First, in the second experiment there were no significant differences in recruit abundance among treatments for any species. Second, there was no significant difference in average recruit size among treatments for any species, indicating that selectivity is unrelated to recruit size. Third, except for one case, there was no evidence that larvae selected or rejected within-reef settlement sites based on the location of piscivores or damselfishes. The single exception was a suggestive pattern for newly settled beaugregory damselfish on reefs with enclosed adult damselfishes $(\mathrm{P}-\mathrm{D}+)$ : more than twice as many recruits were found adjacent to the half of the enclosure containing adult $S$. leucostictus relative to the other half containing adult $S$. partitus.

Although many studies have suggested that nonrandom patterns of recruit distribution are the result of preferences for certain habitats by settling larvae, the unequivocal demonstration of larval settlement preferences is rare (review by Booth and Wellington 1998). Elliot et al. (1995) and Danilowicz (1996) demonstrated that newly settled recruits of some damselfishes (Amphiprion spp. and Dascyllus albisella) prefer certain habitats, which they detect via olfactory cues. Habitat selection by settling larvae was unlikely to explain recruitment differences in the present study because experimental reefs were constructed to minimize habitat variation among reefs (e.g., similar coral composition, reef size, water depth). Sweatman (1988) and Booth (1992) demonstrated that some newly settled damselfishes (Dascyllus spp.) prefer to settle with conspecifics, which they detect via olfactory and visual cues. Larval settlement preferences are likely to develop when recruits derive benefits from selecting, or avoiding, particular habitats or reef residents (Booth and Wellington 1998). For example, Dascyllus spp. recruits sometimes experience enhanced survival in the presence of adults, perhaps because adults are aggressive toward predators or increase group vigilance (Forrester 1990, Booth 1995). Why did settling larvae in the second experiment not make settlement choices based on the presence of resident piscivores and damselfishes, given that the results of the first experiment suggest such choices would be beneficial? A likely precondition for the development of settlement preferences is that cues are taxonomically specific, patchy, and temporally consistent, and piscivores and nonaggregating competitors are unlikely to provide such cues for several reasons (M. S. Webster and G. R. Almany, 
unpublished manuscript). First, unlike Dascyllus spp., the piscivores and damselfishes manipulated in this study do not live in high-density social groups. As a result, any nonvisual cues derived from these fishes are likely to be relatively diffuse and thus difficult to detect. Second, unlike specific types of habitat or dense aggregations of conspecifics, piscivores and competitors are taxonomically diverse and relatively ubiquitous (reviews by Hixon 1991, Ceccarelli et al. 2001). As a result, nonvisual cues would be correspondingly nonspecific, diffuse, and thus difficult to detect. Third, unlike aggregations of Dascyllus spp. and specific habitats, piscivore distributions are not consistent through time, making it difficult to locate temporally predictable piscivore-free patches. For these reasons, it is unlikely that nonvisual cues derived from piscivores and the damselfishes manipulated in this study would provide the necessary information for settling larvae to select or avoid sites where they were present, despite the obvious benefits of such a strategy.

\section{How quickly are recruitment patterns established?}

Results from this study support the prediction that recruitment patterns were established rapidly after settlement. Assuming that differences in recruitment in the first experiment were caused by differential recruit mortality rather than differential settlement, evidence suggests that most mortality occurred within hours of nocturnal settlement. In the first experiment, there were strong differences among treatments in the number of new settlers observed during daily censuses, which generally reflected recruitment patterns. Results from the second experiment suggest that these differences in new settler counts were unlikely to result from differential settlement. Thus, it appears that differences in new settler counts were the result of differential mortality among treatments, and such mortality must have occurred prior to daily morning censuses. Additionally, I tested the hypothesis that the first few daylight hours postsettlement are a critical mortality period for new settlers (Leis 1991, Schmitt and Holbrook 1999) by comparing the number of new settlers observed during early and late morning censuses. If mortality was high during the first daylight hours postsettlement, one would expect to observe fewer new settlers in the late morning relative to the early morning. However, new settler counts were nearly identical for these two periods, suggesting that mortality between these periods was negligible. This observation further supports the conclusion that recruitment patterns were already established, and thus that differential mortality had already occurred, before censusing began at 0800 hours each day.

Several recent studies provide additional evidence that recruits are subject to high mortality within the first 48 hours following settlement. Planes and Lecaillon (2001) experimentally demonstrated that settling larvae of several species experience significantly high- er mortality within 36 hours of settlement when released on reefs with resident fishes, including predators, than when released on reefs where residents had been removed. V. Dufour, M. A. Hixon, P. J. Doherty, R. Galzin, and S. Planes (unpublished manuscript) compared daily estimates of larval supply obtained from crest net catches to daily recruitment surveys in a $1-\mathrm{km}^{2}$ section of the lagoon in Moorea, French Polynesia, and concluded that a large percentage of surgeonfish recruits were consumed prior to daily recruitment surveys. Webster (2002) and Webster and Almany (2002) found that high recruit mortality within 48 hours of settlement explained differences in recruitment between reefs where resident piscivores were present and reefs where piscivores had been removed.

Although results from the present study indicate that recruitment patterns were established by differential mortality that occurred shortly after nocturnal settlement, it is impossible to determine whether mortality was greatest during the night or early morning. However, other evidence suggests that mortality may have been highest during dawn when low, changing light levels confer an advantage to visual piscivores (Hobson 1991, McFarland 1991). Using infrared cameras to monitor the nocturnal behavior of predators, Holbrook and Schmitt (1997) observed that predation risk (mean number of predator visits per hour multiplied by the duration of each visit) was greatest at dawn. Newly settled recruits may be especially vulnerable to predation shortly after settlement due to unfamiliarity with their new surroundings and consequent difficulty in finding adequate, unoccupied shelter.

\section{Why did effects of resident piscivores and damselfishes differ among recruit species?}

Results from the first experiment do not support the prediction that resident piscivores and territorial damselfishes negatively influence recruitment of all species. Rather, effects of residents differed markedly among the three taxonomically diverse species analyzed in this study. Rather surprisingly, (1) the negative effect of adult territorial damselfishes on beaugregory damselfish recruitment was equal in magnitude to the negative effect of resident piscivores, (2) territorial damselfishes had a positive effect on blue tang surgeonfish recruitment, and (3) the presence of resident piscivores enhanced recruitment of bluehead wrasse. Assuming that recruitment patterns were caused by early recruit mortality, what were the likely mechanisms that generated these effects?

Recruitment of beaugregory damselfish (Stegastes leucostictus) was uniformly low where either piscivores or territorial damselfishes were present alone $(\mathrm{P}+\mathrm{D}-$ and $\mathrm{P}-\mathrm{D}+)$, or where both groups were present $(\mathrm{P}+\mathrm{D}+)$. How might adult territorial damselfishes influence juvenile survival? One possibility is that aggressive interactions between adult damselfishes and juveniles made juveniles more susceptible to predation 
by resident piscivores (on $\mathrm{P}+\mathrm{D}+$ reefs) and/or transient piscivores (on $\mathrm{P}-\mathrm{D}+$ reefs), such as schooling jacks (see Hixon and Carr 1997). Adults often chase juveniles (personal observation), which might expose them to predation by resident piscivores, or force them to the edge of the reef where they might be more susceptible to passing transient piscivores. Another possibility is that adult damselfishes directly consumed newly settled juveniles. Although I know of no other studies that have explored this hypothesis, Randall's (1967) gut content analysis of 41 adult S. leucostictus revealed that they consume a considerable amount of fish material ( $7.1 \%$ by volume), but whether this material was scavenged from already-dead fishes or resulted from direct predation is unknown. Consistent with this hypothesis, I have observed adults of both $S$. leucostictus and $S$. partitus attack and consume disoriented conspecific and congeneric recruits that had been captured for tagging and/or measuring and released. This observation suggests that adults may opportunistically consume recruits, which could have additional benefits in that it would eliminate some future resource competitors. A similar effect was observed between mosquito larvae and toad tadpoles, which compete for resources when they concurrently enter a community, as do damselfishes. When mosquito larvae preceded toad tadpoles, they preyed on tadpoles (Blaustein and Margalit 1996).

In contrast to damselfish recruitment, recruitment of surgeonfish (Acanthurus coeruleus) was significantly enhanced on reefs where only adult damselfishes were present $(\mathrm{P}-\mathrm{D}+)$. How might adult damselfishes enhance surgeonfish recruitment? In the absence of resident piscivores, the primary source of recruit mortality would most likely be transient piscivores (Hixon and Carr 1997). Because Caribbean Stegastes species often act aggressively toward intruding transient piscivores (personal observation), juvenile surgeonfish may obtain antipredator benefits from damselfish aggression, especially if damselfishes are not also strongly aggressive toward surgeonfishes. Low levels of aggression between surgeonfishes and damselfishes have been documented in other systems, where these fishes actually share in defense of jointly occupied territories (Robertson and Polunin 1981, Roberts 1985). The results of the present study indicate that positive effects of adult damselfishes are negated by the presence of resident piscivores.

In contrast to both damselfish and surgeonfish, wrasse recruitment (Thalassoma bifasciatum) was highest on reefs with resident piscivores $(\mathrm{P}+\mathrm{D}+$ and $\mathrm{P}+\mathrm{D}-$ ). Why might piscivores have a positive effect on $T$. bifasciatum recruitment? Juvenile $T$. bifasciatum are facultative cleaners that remove ectoparasites from other fishes (Itzkowitz 1979). Each piscivore treatment included several Nassau grouper (Epinephelus striatus), which were the largest fishes on these reefs. Because parasite load is correlated with host fish size
(Arnal et al. 2000), juvenile T. bifasciatum might have had access to a greater food supply on reefs with piscivores, which may have increased their survival. In addition, mortality from predation is often greatly reduced for cleaners (Poulin and Vickery 1995), and Carr and Hixon (1995) found that resident piscivores did not negatively affect the survival of transplanted, recently settled $T$. bifasciatum.

\section{Conclusions}

Ecological communities are rarely devoid of established residents. As a result, and regardless of the nature of juvenile supply, incoming juveniles immediately come into contact with a community's current residents. Results from this study demonstrate that the effects on juvenile persistence of resident-juvenile interactions depended on the identity of both the resident and the juvenile; in other words, effects were species specific. Because effects were species specific, these interactions were likely to influence subsequent community structure by altering the initial patterns of relative abundance generated by juvenile supply. For example, in this study prior residency by both piscivores and adult damselfishes reduced damselfish and surgeonfish recruitment, and enhanced wrasse recruitment. In contrast, removal of both piscivores and damselfishes enhanced damselfish recruitment, reduced wrasse recruitment, and resulted in intermediate levels of surgeonfish recruitment. These recruitment differences persisted throughout the 44-d experiment and were thus likely to be reflected in later community structure, although long-term monitoring would be necessary to determine to what extent this were true.

This study supports the view that initial patterns of abundance generated by larval supply can be quickly, and strongly, modified by postsettlement interactions between juveniles and residents. Indeed, given the conclusion that most differential mortality occurred prior to early-morning censuses, it is doubtful whether recruitment surveys can provide accurate estimates of larval settlement, regardless of sampling frequency. Effects of residents on juvenile persistence often appear to be strongest shortly after juveniles enter the community, perhaps because relatively small juveniles are subject to predation from a wider range of predators, and are less able to compete, than larger individuals. For example, small tree seedlings experience greater mortality from consumption by meadow voles than do large seedlings (Ostfeld et al. 1997), tadpoles are subject to predation by mosquito larvae when newly emerged, but not later (Blaustein and Margalit 1996), and newly settled algae suffer higher mortality from consumption by snails than do larger, older algae (Lubchenco 1986).

In previous studies of coral reef fishes that reported effects of residents on subsequent recruitment, it was unclear whether such effects were due to differential juvenile mortality or differential larval settlement. The 
combined results of this study suggest that differential mortality was the cause of recruitment differences in this experimental system, which was designed to minimize habitat variation among replicate reefs. For reasons already discussed, residents such as predators and nonaggregating competitors are unlikely to provide reliable larval settlement cues. However, specific types of habitat, which tend to be patchy and persist through time, are an ideal source of settlement cues, and further studies may demonstrate that habitat selection by settling juveniles is common, especially when juvenile survival is habitat dependent. The relative influence of (1) habitat selection and habitat-mediated survival, and (2) interactions between juveniles and residents on community structure remains unresolved, but is likely to depend on a variety of factors, such as the amount of existing habitat variability, the prevalence of habitat selection by larvae, and the influence of habitat on resident-juvenile interactions. In less variable habitats, resident-juvenile interactions may exert a strong influence on community structure, while in more variable habitats where habitat selection by larvae is common, resident-juvenile interactions may be less influential.

Results from the present study support a dynamic view of coral reef fish communities, in which both stochastic and more deterministic processes influence community structure. Although stochastic larval supply may determine the initial species composition and relative abundance of juveniles entering a community, this study demonstrates that early interactions between residents and juveniles can strongly influence which juveniles persist. As a result, the future development of the community may partially depend on its past recruitment history and on the persistence of established residents. For example, the arrival of a predator may strongly influence subsequent community structure if some species are reduced or excluded and others thrive as a result of interactions with the predator. Similarly, when a predator leaves the community, perhaps through an ontogenetic habitat shift (e.g., Dahlgren and Eggleston 2000) or natural mortality, subsequent community structure is likely to differ from that when the predator was present, as those species previously excluded or reduced by the predator thrive, while others that benefited from the predator's presence decline. Furthermore, when resident-juvenile interactions are species specific, as in the present study, understanding such interactions may provide a qualitative means of predicting the future structure of an open community based on its current structure. Understanding the nature of resident-juvenile interactions in this and other systems may therefore prove useful in predicting how anthropogenic disturbances, such as removing predators for human consumption, are likely to influence the dynamics of open communities.

\section{ACKNOWLEDGMENTS}

I am especially grateful to $\mathrm{M}$. Webster for assistance in the field. I thank T. Anderson, D. Booth, B. Byrne, M. Carr, G.
Forrester, M. Hixon, B. Menge, K. Overholtzer, D. Piechnik, S. Sogard, and M. Steele for many beneficial discussions, and the staff and interns of the Caribbean Marine Research Center, especially B. Kakuk, R. McCaffery, J. and J. Tryzbiak, R. and P. Tryzbiak, T. Wolcott, and C. Wormald, for logistical support. I am grateful to D. Derryberry, P. Murtaugh, and C. Pereira for advice on statistics. Financial support for this study was provided by the Professional Association of Diving Instructors (PADI-Project AWARE), Sigma Xi, Oregon State University Zoology Research Funds, an NSF Graduate Predoctoral Fellowship to the author, and NSF grants (OCE96-17483 and OCE-00-93976) and NOAA-NURP grants (CMRC-95-3042 and CMRC-97-3109) to M. Hixon. This is a chapter from my doctoral dissertation, which benefited from advice and reviews by my graduate committee: M. Hixon (chair), B. Menge, M. Carr, S. Sogard, and P. Bayley. Additional reviews were provided by K. Overholtzer, M. Webster, and two anonymous reviewers. This paper is dedicated to the memory of my beloved friend and companion, Kitka.

\section{Literature Cited}

Alford, R. A., AND H. M. Wilbur. 1985. Priority effects in experimental pond communities: competition between Bufo and Rana. Ecology 66:1097-1105.

Anderson, T. W., and M. H. Carr. 1998. BINCKE: a highly efficient net for collecting reef fishes. Environmental Biology of Fishes 51:111-115.

Arnal, C., I. M. Cote, P. Sasal, and S. Morand. 2000. Cleanerclient interactions on a Caribbean reef: influence of correlates of parasitism. Behavioral Ecology and Sociobiology 47:353-358.

Ault, T. R., and C. R. Johnson. 1998. Spatially and temporally predictable fish communities on coral reefs. Ecological Monographs 68:25-50.

Beets, J. 1997. Effects of a predatory fish on the recruitment and abundance of Caribbean coral reef fishes. Marine Ecology Progress Series 148:11-21.

Bertness, M. D., and S. W. Shumway. 1993. Competition and facilitation in marsh plants. American Naturalist 142:718724.

Beukers, J. S., and G. P. Jones. 1997. Habitat complexity modifies the impact of piscivores on a coral reef fish population. Oecologia 114:50-59.

Blaustein, L., and J. Margalit. 1996. Priority effects in temporary pools: nature and outcome of mosquito larva-toad tadpole interactions depend on order of entrance. Journal of Animal Ecology 65:77-84.

Booth, D. J. 1992. Larval settlement patterns and preferences by domino damselfish Dascyllus albisella Gill. Journal of Experimental Marine Biology and Ecology 155:85-104.

Booth, D. J. 1995. Juvenile groups in a coral-reef damselfish: density-dependent effects on individual fitness and demography. Ecology 76:91-106.

Booth, D. J., and G. Wellington. 1998. Settlement preferences in coral-reef fishes: effects on patterns of adult and juvenile distributions, individual fitness and population structure. Australian Journal of Ecology 23:274-279.

Burrows, C. J. 1990. Processes of vegetation change. Unwin Hyman, Winchester, Massachusetts, USA.

Caley, M. J. 1993. Predation, recruitment and the dynamics of communities of coral-reef fishes. Marine Biology 117: 33-43.

Caley, M. J. 1998. Age-specific mortality rates in reef fishes: evidence and implications. Australian Journal of Ecology 23:241-245.

Carr, M. H., and M. A. Hixon. 1995. Predation effects on early post-settlement survivorship of coral-reef fishes. Marine Ecology Progress Series 124:31-42.

Ceccarelli, D. M., G. P. Jones, and L. J. McCook. 2001. Territorial damselfishes as determinants of the structure of ben- 
thic communities on coral reefs. Oceanography and Marine Biology: an Annual Review 39:355-389.

Connell, J. H. 1961. The influence of interspecific competition and other factors on the distribution of the barnacle Cthamalus stellatus. Ecology 42:710-723.

Connolly, S. R., and J. Roughgarden. 1999. Theory of marine communities: competition, predation, and recruitment-dependent interaction strength. Ecological Monographs 69: 277-296.

Dahlgren, C. P., and D. B. Eggleston. 2000. Ecological processes underlying ontogenetic habitat shifts in a coral reef fish. Ecology 81:2227-2240.

Danilowicz, B. S. 1996. Choice of coral species by naive and field-caught damselfish. Copeia 1996:735-739.

Doherty, P. J. 1982. Some effects of density on the juveniles of two species of tropical, territorial damselfishes. Journal of Experimental Marine Biology and Ecology 65:249-261.

Doherty, P. J., and D. M. Williams. 1988. The replenishment of coral reef fish populations. Oceanography and Marine Biology: an Annual Review 26:487-551.

Elliot, J. K., J. M. Elliot, and R. N. Mariscal. 1995. Host selection, location, and association behaviors of anemonefishes in field settlement experiments. Marine Biology 122:377-389.

Emery, A. R. 1973. Comparative ecology and functional osteology of fourteen species of damselfish (Pisces: Pomacentridae) at Alligator Reef, Florida Keys. Bulletin of Marine Science 23:649-770.

Forrester, G. E. 1990. Factors influencing the juvenile demography of a coral reef fish. Ecology 71:1666-1681.

Hixon, M. A. 1991. Predation as a process structuring coral reef fish communities. Pages 475-508 in P. F. Sale, editor. The ecology of fishes on coral reefs. Academic Press, San Diego, California, USA.

Hixon, M. A., and J. P. Beets. 1989. Shelter characteristics and Caribbean fish assemblages: experiments with artificial reefs. Bulletin of Marine Science 44:666-680.

Hixon, M. A., and M. H. Carr. 1997. Synergistic predation, density dependence, and population regulation in marine fish. Science 277:946-949.

Hixon, M. A., and M. S. Webster. 2002. Density dependence in reef fish populations. Pages 303-325 in P. F. Sale, editor. Coral reef fishes: dynamics and diversity in a complex ecosystem. Academic Press, San Diego, California, USA.

Hobson, E. S. 1991. Trophic relationships of fishes specialized to feed on zooplankters above coral reefs. Pages 6995 in P. F. Sale, editor. The ecology of fishes on coral reefs. Academic Press, San Diego, California, USA.

Holbrook, S. J., and R. J. Schmitt. 1997. Settlement patterns and process in a coral reef damselfish: in situ nocturnal observations using infrared video. Proceedings of the 8 th International Coral Reef Symposium 2:1143-1148.

Huston, M., and T. Smith. 1987. Plant succession: life history and competition. American Naturalist 130:168-198.

Itzkowitz, M. 1979. The feeding strategies of a facultative cleanerfish, Thalassoma bifasciatum (Pisces: Labridae). Journal of Zoology 187:403-413.

Jones, G. P. 1987. Some interactions between residents and recruits in two coral reef fishes. Journal of Experimental Marine Biology and Ecology 114:169-182.

Jones, G. P. 1991. Postrecruitment processes in the ecology of coral reef fish populations: a multifactorial perspective. Pages 294-328 in P. F. Sale, editor. The ecology of fishes on coral reefs. Academic Press, San Diego, California, USA.

Jones, G. P., M. J. Milicich, M. J. Emslie, and C. Lunow. 1999. Self-recruitment in a coral reef fish population. Nature 402:802-804.

Kaufman, L., J. Ebersole, J. Beets, and C. C. McIvor. 1992. A key phase in the recruitment dynamics of coral reef fish- es: post-settlement transition. Environmental Biology of Fishes 34:109-118.

Knowlton, N., and J. B. C. Jackson. 2001. The ecology of coral reefs. Pages 395-422 in M. D. Bertness, S. D. Gaines, and M. E. Hay, editors. Marine community ecology. Sinauer Associates, Sunderland, Massachusetts, USA.

Lawler, S. P., and P. J. Morin. 1993. Temporal overlap, competition, and priority effects in larval anurans. Ecology 74: 174-182.

Leis, J. M. 1991. The pelagic stage of reef fishes: the larval biology of coral reef fishes. Pages 183-230 in P. F. Sale, editor. The ecology of fishes on coral reefs. Academic Press, San Diego, California, USA.

Leis, J. M., and M. I. McCormick. 2002. The biology, behaviour and ecology of the pelagic, larval stage of coralreef fishes. Pages 171-199 in P. F. Sale, editor. Coral reef fishes: dynamics and diversity in a complex ecosystem. Academic Press, San Diego, California, USA.

Lubchenco, J. 1986. Relative importance of competition and predation: early colonization by seaweeds in New England. Pages 537-555 in J. M. Diamond and T. Case, editors. Community ecology. Harper and Row, New York, New York, USA.

McFarland, W. N. 1991. The visual world of coral reef fishes. Pages 16-38 in P. F. Sale, editor. The ecology of fishes on coral reefs. Academic Press, San Diego, California, USA.

Menge, B. A., and J. P. Sutherland. 1987. Community regulation: variation in disturbance, competition, and predation in relation to environmental stress and recruitment. American Naturalist 130:730-757.

Morgan, S. G. 2001. The larval ecology of marine communities. Pages 159-181 in M. D. Bertness, S. D. Gaines, and M. E. Hay, editors. Marine community ecology. Sinauer Associates, Sunderland, Massachusetts, USA.

Morin, P. J. 1999. Community ecology. Blackwell Science, Malden, Massachusetts, USA.

Ostfeld, R. S., R. H. Manson, and C. D. Canham. 1997. Effects of rodents on survival of tree seeds and seedlings invading old fields. Ecology 78:1531-1542.

Planes, S., and G. Lecaillon. 2001. Caging experiment to examine mortality during metamorphosis of coral reef fish larvae. Coral Reefs 20:211-218.

Poulin, R., and W. L. Vickery. 1995. Cleaning symbiosis as an evolutionary game: to cheat or not to cheat? Journal of Theoretical Biology 175:63-70.

Ramsey, F. L., and D. W. Schafer. 1997. The statistical sleuth: a course in methods of data analysis. Duxbury Press, Belmont, California, USA.

Randall, J. E. 1967. Food habits of reef fishes of the West Indies. Studies in Tropical Oceanography 5:665-847.

Risk, A. 1998. The effects of interactions with reef residents on the settlement and subsequent persistence of ocean surgeonfish, Acanthurus bahianus. Environmental Biology of Fishes 51:377-389.

Roberts, C. M. 1985. Resource sharing in territorial herbivorous reef fishes. Proceedings of the 5th International Coral Reef Congress 4:17-22.

Robertson, D. R. 1996. Interspecific competition controls abundance and habitat use of territorial Caribbean damselfishes. Ecology 77:885-899.

Robertson, D. R., and V. C. Polunin. 1981. Coexistence: symbiotic sharing of feeding territories and algal food by some coral reef fishes from the western Indian Ocean. Marine Biology 62:185-195.

Sale, P. F. 1976. The effect of territorial adult pomacentrid fishes on the recruitment and survival of juveniles on patches of coral rubble. Journal of Experimental Marine Biology and Ecology 24:297-306.

Sale, P. F. 1980. Assemblages of fish on patch reefs-predictable or unpredictable? Environmental Biology of Fishes 5:243-249. 
Sale, P. F. 1991. Introduction. Pages 3-15 in P. F. Sale, editor. The ecology of fishes on coral reefs. Academic Press, San Diego, California, USA.

Sale, P. F., and W. A. Douglas. 1984. Temporal variability in the community structure of fish on coral patch reefs and the relation of community structure to reef structure. Ecology 65:409-422.

Sale, P. F., J. A. Guy, and W. J. Steel. 1994. Ecological structure of assemblages of coral reef fishes on isolated patch reefs. Oecologia 98:83-99.

SAS Institute. 1989. SAS/STAT user's guide. Version 6 Fourth edition. SAS Institute, Cary, North Carolina, USA.

SAS Institute. 2000. JMP user's guide. Version 4. SAS Institute, Cary, North Carolina, USA.

Schmitt, R. J., and S. J. Holbrook. 1999. Mortality of juvenile damselfish: implications for assessing processes that determine abundance. Ecology 80:35-50.

Shulman, M. J., J. C. Ogden, J. P. Ebersole, W. N. McFarland, S. L. Miller, and N. G. Wolf. 1983. Priority effects in the recruitment of juvenile coral reef fishes. Ecology 64:15081513 .

Sokal, R. R., and F. J. Rohlf, editors. 1995. Biometry. Third edition. W. H. Freeman, New York, New York, USA.

Sousa, W. P. 1979. Disturbance in marine intertidal boulder fields: the nonequilibrium maintenance of species diversity. Ecology 60:1225-1239.

Steele, M. A. 1997. The relative importance of processes affecting recruitment of two temperate reef fishes. Ecology 78: $129-145$.
Swearer, S. E., J. E. Caselle, D. W. Lea, and R. R. Warner. 1999. Larval retention and recruitment in an island population of a coral-reef fish. Nature 402:799-802.

Sweatman, H. P. A. 1983. Influence of conspecifics on choice of settlement sites by larvae of two pomacentrid fishes (Dascyllus aruanus and D. reticulatus) on coral reefs. Marine Biology 75:225-229.

Sweatman, H. P. A. 1985. The influence of adults of some coral reef fishes on larval recruitment. Ecological Monographs 55:469-485.

Sweatman, H. P. A. 1988. Field evidence that settling coral reef fish larvae detect resident fishes using dissolved chemical cues. Journal of Experimental Marine Biology and Ecology 124:163-174.

Syms, C., and G. P. Jones. 2000. Disturbance, habitat structure, and the dynamics of a coral-reef fish community. Ecology 81:2714-2729.

Victor, B. C. 1991. Settlement strategies and biogeography of reef fishes. Pages 231-260 in P. F. Sale, editor. The ecology of fishes on coral reefs. Academic Press, San Diego, California, USA.

Webster, M. S. 2002. Role of predators in the early postsettlement demography of coral-reef fishes. Oecologia 131: $52-60$.

Webster, M. S., and G. R. Almany. 2002. Positive indirect effects in a coral reef fish community. Ecology Letters 5: 549-557.

Wilbur, H. M., and R. A. Alford. 1985. Priority effects in experimental pond communities: responses of Hyla to Bufo and Rana. Ecology 66:1106-1114. 